\title{
Motivação para a permanência na profissão: a percepção dos docentes universitários
}

\author{
Tárcia Rita Davoglio \\ Pontifícia Universidade Católica do Rio Grande do Sul - Porto Alegre - RS - Brasil \\ Carla Spagnolo \\ Pontifícia Universidade Católica do Rio Grande do Sul - Porto Alegre - RS - Brasil \\ Bettina Steren dos Santos \\ Pontifícia Universidade Católica do Rio Grande do Sul - Porto Alegre - RS - Brasil
}

\begin{abstract}
Resumo
Este estudo qualitativo visou conhecer os principais aspectos que motivam os docentes da Educação Superior à permanência na carreira. Os dados foram coletados com 26 professores, os quais apontaram os aspectos percebidos como essenciais para a sua permanência, e agrupados segundo os princípios da análise de conteúdo. Emergiram10 categorias, hierarquizadas pela frequência: relação com alunos; formação continuada; gosto/ prazer/satisfação pela docência; envolvimento com a pesquisa científica; salário; contribuição social da atuação; ambiente acadêmico, autonomia, segurança/estabilidade/prestígio e desafios/compartilhamento do conhecimento. Os resultados foram discutidos à luz das teorias contemporâneas sobre os processos motivacionais e convergem com a literatura atual sobre a temática. Acreditamos que as categorias que emergiram como motivos para a permanência na carreira docente possam oferecer subsídios empíricos que contribuam para o estabelecimento de correlações entre fatores individuais, contextuais e motivação percebida, úteis na promoção do desenvolvimento e da qualidade da docência na Educação Superior.
\end{abstract}

Palavras-chave: Motivação; Professores; Educação Superior.

\section{Motivation to remain in the profession: the perception of university teachers}

\begin{abstract}
This qualitative study aimed to know the main aspects that motivate higher education teachers to stay in the career. The data were collected with 26 teachers, who pointed out the aspects perceived as essential for their permanence, which were grouped according to the principles of content analysis. Ten categories emerged, hierarchized by frequency: relationship with students; Continuing education; Taste / pleasure / satisfaction for teaching; Involvement with scientific research; salary; Social contribution of the action; Academic environment, autonomy, security / stability / prestige and challenges / knowledge sharing. The results were discussed in light of contemporary theories on motivational processes and converge with current literature on the subject. We believe that the categories that emerged as motives for the permanence of the teaching career can offer empirical supports that contribute to the establishment of correlations between individual, contextual factors and perceived motivation, useful in promoting the development and quality of teaching in Higher Education.
\end{abstract}

Keywords: Motivation; Teachers; Higher education.

\section{Motivación para la permanencia en la profesión: la percepción de los docentes universitarios}

\begin{abstract}
Resumen
Este estudio cualitativo tuvo por objetivo conocer los principales aspectos que motivan a los docentes de la Educación Superior a la permanencia en la carrera. Se recolectaron los datos con 26 profesores los cuales apuntaron los aspectos percibidos como esenciales para su permanencia, los dados agruparon según los principios del análisis de contenido.Emergieron10 categorías, jerarquizadas por la frecuencia: relación con alumnos; formación continuada; gusto/placer/satisfacción por la docencia; compromiso con la investigación científica; remuneración; contribución social de la actuación; ambiente académico, autonomía, seguridad/estabilidad/prestigio y desafíos/intercambio del conocimiento. Se discutieron los resultados a la luz de las teorías contemporáneas sobre los procesos motivacionales y convergen con la literatura actual sobre la temática. Creemos que las categorías que surgieron como motivos para la permanencia en la carrera docente puedan ofrecer subsidios empíricos que contribuyan al establecimiento de correlaciones entre factores individuales, contextuales y motivación percibida, útiles en la promoción del desarrollo y de la calidad de la docencia en la Educación Universitaria.
\end{abstract}

Palabras clave: Motivación; Profesores; Educación Universitaria. 


\section{Introdução}

A importância dos professores para a garantia da qualidade da educação é indiscutível e, inevitavelmente, remete à motivação para permanecer na carreira docente, levando em consideração tanto aspectos pessoais quanto profissionais.

No contexto específico da Educação Superior, o desenvolvimento profissional docente requer a consideração às mudanças do cenário acadêmico, em decorrência das transformações sociais e políticas. O docente do ensino superior é responsável por identificar e gerir contradições, desafios, dilemas e possibilidades do seu trabalho, estando atento ao ritmo das mudanças e mantendo uma atitude de suspeição em relação aos fundamentos de sua atuação profissional (Bittar, Oliveira, \& Morosini, 2008).

A profissão docente pode ser vivenciada distintamente ao longo da carreira. Jesus e Santos (2004) explicam as quatro fases que podem implicar na motivação. A primeira fase, a exploração, corresponde ao período inicial da carreira, isto é, durante os primeiros dois ou três anos de serviço. Nesta fase, o professor experimenta papéis e avalia a sua competência profissional, podendo daí resultar três configurações motivacionais: (1) sobrevivência, se o confronto com a realidade escolar tiver sido problemático, nomeadamente pela ocorrência de fracassos na dinâmica estabelecida no processo de ensino-aprendizagem; (2) descoberta, se for experiência do sucesso, entusiasmo e satisfação com as novas experiências; (3) indiferença, se o professor escolheu a profissão docente por falta de outras alternativas profissionais. O modo como essas fases são vivenciadas, então, tanto podem gerar satisfação quanto frustração, promovendo, ou não, seu bem-estar na carreira.

Contudo, desde o início do século XXI, estudiosos como Jesus (2004) vêm alertando que os docentes sofrem de uma espécie de crise de identidade, pois têm dificuldade em estabelecer limites e objetivos para a sua atividade profissional, desconhecendo até mesmo o que fundamenta a sua permanência na carreira. Nessa perspectiva os professores, não raras vezes, sentem-se descontextualizados diante das muitas exigências profissionais e no confronto com a sociedade do conhecimento. Para o autor, a crise se estabelece pela distância entre o que os professores gostariam de exercer e as práticas que efetivamente realizam, entrando em jogo fatores motivacionais.

Professores motivados para aprender e ensinar tendem a potencializar sua prática educativa cotidiana e ao mesmo tempo conseguem estimular os educandos para engajarem-se na aprendizagem. Pensar a motivação envolve uma diversidade de variáveis, englobando motivos intrínsecos (ou seja, oriundos das expectativas e valores internos) e extrínsecos (isto é, oriundos do ambiente e dos elementos sociais). Assim, a motivação revela-se um processo multifacetado que inclui fatores cognitivos, relacionais e afetivos que influenciam nas escolhas, iniciativas, direções e qualidade de uma ação para atingir um objetivo determinado (Huertas, 2001).

De acordo com Sánchez-Sellero, Sánchez-Sellero, Cruz-González e Sánchez-Sellero (2014), entende-se por motivação laboral os estímulos que conduzem às maneiras qualitativamente distintas de atuar no trabalho, oriundas do próprio ambiente de trabalho ou das relações sociais. A satisfação no trabalho é diretamente influenciada pela motivação, e segundo Kanfer (1995), esta possui uma relação de reciprocidade com o rendimento laboral, afetando-se mutuamente.

Embora existam inúmeras concepções acerca da motivação, a Teoria da Autodeterminação (Self-Determination Theory - SDT; Deci \& Ryan, 2000, 2008) embasa muitos estudos contemporâneos sobre a temática. A SDT foca-se no comportamento autodeterminado, apoiado em motivações intrínsecas e nas condições sociais e ambientais que o promovem. Pressupõe a existência de um conjunto de necessidades psicológicas básicas (NPB) e universais, denominadas autonomia, competência e pertencimento, que, quando satisfeitas conjuntamente, promovem o funcionamento humano saudável em todas as suas dimensões, independentemente da cultura ou estágio de desenvolvimento que o indivíduo se encontre (Deci \& Ryan, 2000).

Para a SDT, a motivação depende de regulação autônoma ou controlada. A motivação autônoma implica a vontade própria e a ação deliberada, ou seja, motivação intrínseca, a qual pressupõe um interesse genuíno por uma ação, independendo de recompensas ou valoração externa. A motivação intrínseca é autorregulada porque se fundamenta nas escolhas, interesses e valores significativos para a pessoa. No entanto, pode incluir alguns tipos de motivação extrínseca, nas quais o sujeito se identifica com o sentido da ação e vai, gradualmente, integrando-o aos seus valores e princípios. A motivação controlada, por outro lado, pressupõe algum tipo de regulação externa do comportamento, por meio de recompensas ou punições, ou coerção, aprovação. A motivação controlada implica em pressão para pensar, agir ou sentir de uma forma específica, que não corresponde àquela que deriva do livre arbítrio. Segundo a SDT tanto a motivação autorregulada quanto a controlada se opõem à motivação, isto é, a ausência de motivação para um comportamento (Deci \& Ryan, 2000).

Sendo a motivação um processo psicológico complexo e determinante para as ações e escolhas do indivíduo, caracterizando-se como componente essencial para a produção de sentido na docência, emergem indagações sobre os motivos que sustentam a permanência dos professores na carreira docente. Buscar conhecer a motivação percebida pelos próprios professores, revelando o que dá sentido e promove a sua permanência na carreira é o foco principal deste estudo.

\section{Percurso metodológico}

O objetivo desta pesquisa qualitativa exploratória descritiva foi conhecer os principais aspectos que motivam os professores da Educação Superior à permanência na carreira, a partir das suas próprias percepções. Com esse intuito, 26 professores de instituições de educação superior (IES) públicas e privadas, ativos nas funções docentes na 
graduação e/ou pós-graduação, foram solicitados - por meio de um questionário autoaplicável, que integra um protocolo de pesquisa mais amplo sobre processos motivacionais docentes - a apontar os aspectos percebidos como essenciais para a sua permanência na docência, bem como a fornecer informações sociodemográficas, tais como idade, estado civil, titulação acadêmica, tempo de docência e remuneração; essas informações foram analisadas do ponto de vista descritivo. Os professores foram escolhidos aleatoriamente, após conhecerem os objetivos da pesquisa, e só incluídos na pesquisa aqueles que concordaram em participar da coleta de forma voluntária e anônima, assinando o termo de consentimento livre e esclarecido, conforme as diretrizes do Comitê de Ética em Pesquisa (protocolo de aprovação CEP 10/05132). As informações provenientes da questão "Descreva o que motiva a sua permanência na carreira docente" foram agrupadas segundo os princípios da análise de conteúdo (Bardin, 2011), emergindo categorias, as quais foram hierarquizadas por ordem de relevância, considerando-se a frequência com que os conteúdos se repetiram. Em seguida foram analisadas, interpretadas e debatidas com base na literatura, promovendo entrelaçamentos dialógicos.

\section{Resultados e Discussão}

As informações sociodemográficas revelaram que a idade dos 26 professores incluídos no estudo variou entre 29 e 63 anos $(M=45,5 ; D P=9,0)$. A titulação acadêmica de 18 professores era de mestrado $(69,2 \%)$ e de sete era de doutorado ou pós-doutorado (26,9\%), havendo somente um participante com a titulação de especialista. Tais resultados confirmam a tendência de crescimento da titulação acadê- mica entre os docentes observada desde os anos de 1990 , especialmente, no estado do Rio Grande do Sul (Morosini \& Rossato, 2006).

O tempo médio de atuação docente dos professores pesquisados foi de 17 anos (DP=12,2) e a faixa salarial de até cinco mil reais foi a que concentrou maior número de professores (34,6\%), revelando que o aumento da remuneração tende a não acompanhar linearmente o tempo de trabalho. A maioria $(53,8 \%)$ evidenciou dedicação exclusiva à docência, porém, somente sete professores atuavam apenas em sala de aula (26,9\%), os demais acumulavam outras atividades acadêmicas, além da sala de aula. Entende-se que o exercício concomitante de múltiplas atividades na carreira caracteriza a educação superior atual, sendo uma prática prevalente entre os docentes brasileiros, exigindo habilidades e motivação para o desempenho de diferentes papéis, que envolvem desde ministrar aulas até rotinas de gestão e pesquisa. Evidencia-se, assim, certa valoração em termos de habilidades e competências que, muitas vezes, se sobrepõe ao conhecimento e experiência didática e pedagógica e à postura epistemológica que favorece a interpretação dos acontecimentos do mundo e a aprendizagem e o conhecimento socialmente relevante, atendendo ao chamado "produtivismo acadêmico" (Silva \& Beraldo, 2008, p.322), pautado no fazer cada vez mais diversificado, podendo comprometer tanto a motivação quanto a qualidade do trabalho docente.

Quanto à motivação, os resultados da pesquisa revelaram dez categorias que emergiram como principais motivadores à permanência na carreira docente para os professores pesquisados, cuja hierarquia foi estabelecida com base na frequência com que foram observadas nas respostas, como mostra a Figura 1.

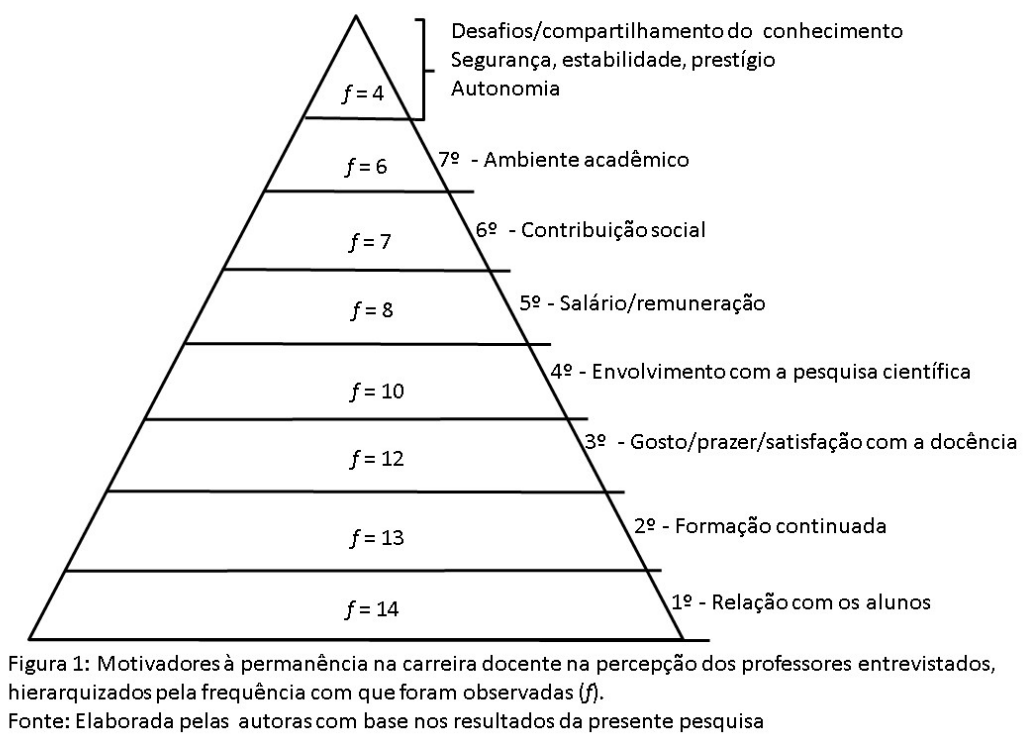

Figura 1. Principais motivadores à permanência na carreira docente na percepção dos professores entrevistados, hierarquizados pela frequência com que foram observadas $(f)$. Nota. Elaborada pelas autoras com base nos resultados 
O primeiro aspecto evidenciado como relevante para os docentes pesquisados foi a relação com os alunos, trazendo indicativos positivos sobre a gratificação obtida nos processos de ensino e de aprendizagem e nas relações interpessoais que convergem para produção e apropriação do conhecimento. Na medida em que os professores consideram a sala de aula como lugar de relacionamento, passam a vislumbrar um horizonte mais amplo de possibilidades, incluindo a didática e as metodologias. Nesse sentido, o modo como se efetiva a relação entre os docentes e discentes influencia tanto no aprendizado dos conteúdos que são ministrados como na satisfação pessoal e profissional do professor (Gil, 2012). Por isso, para que a atuação docente se efetive, e a aprendizagem ocorra, é necessária a criação de espaços de diálogo, em que professores e alunos possam exercitar seus mecanismos de compreensão e empatia, onde os vínculos se consolidam e se renovam continuamente (Matos \& Hobold, 2015).

O diálogo coletivo e os vínculos relacionais são condição indispensável ao enriquecimento docente e, na percepção destes professores, a principal razão para permanecerem na carreira (Isaia, 2006). As relações emocionais, de acordo com Marchesi (2008), devem ter congruência com as vivências no trabalho e as relações afetivas com os alunos, a interação com os pais, a adaptação às reformas na educação e a compreensão das próprias emoções.

O segundo motivo mais relevante para a permanência na docência entre os professores pesquisados foi a formação continuada de professores, a qual é essencial para desenvolvimento de capacidades e habilidades nos eixos científico, pedagógico e empírico (Grillo \& Mattei, 2005). Tem por objetivo qualificar e instrumentalizar o professor não apenas do ponto de vista técnico, mas também na prática reflexiva para a compreensão da diversidade e na ascensão pelo gosto de educar. De acordo com Santos e Antunes (2013), ser educador é também ser sujeito único em características humanas, em um processo de desenvolvimento contínuo, com ações educativas que considerem fundamentalmente a singularidade das pessoas.

Tardif (2013) vincula a formação continuada aos saberes docentes, os quais se compõem de conhecimentos provenientes de diferentes fontes. No entanto, o autor afirma que se a formação estiver baseada unicamente pelos conhecimentos científico-disciplinares não há conexão com a ação profissional, ocasionando impotência e falta de sentido na formação dos professores. Tal fato suscita apreciação de saberes que integrem e incorporem os conhecimentos do currículo, profissionais e da experiência dos professores, inseridos em um determinado contexto sócio-histórico.

Para Veiga e Viana (2011), a formação deve levar os professores a entender as transformações e contradições sociais, sob o ponto de vista do desenvolvimento de habilidades para trabalhar coletivamente e, nesse sentido, engajando-o com o contexto acadêmico local e global. Segundo esses autores, a motivação para aprender no processo de formação continuada está interligada com: redes de conhecimento, visão compartilhada e interação entre as pessoas; investigação de novos enfoques e aprendizagens com experiências passadas sem permanecer nelas; reações proativas na resolução de problemas; criatividade para propiciar novos espaços de aprendizagem; práticas inovadoras; planejamento flexível para atuação com maior autonomia. Todos esses aspectos citados podem ser determinantes para a satisfação na docência se forem contemplados e incentivados no cotidiano docente.

O gosto/prazer/satisfação pela docência foi a terceira categoria que emergiu, levando em consideração que as escolhas pessoais são decisivas no envolvimento com as tarefas. Os fatores intrínsecos da atividade docente são, sobretudo, os que mais influenciam na escolha desta profissão, como por exemplo, o gostar de ensinar e de contribuir com o desenvolvimento dos alunos (Jesus, 1996). Para isso, é fundamental o exercício da reflexão autocrítica e a consciência das próprias atitudes. O gosto e a satisfação pela prática docente também são percebidos pelas atitudes positivas, pela boa disposição nos vínculos interpessoais no meio acadêmi$\mathrm{co}$, na atitude colaborativa com colegas e pelo bom humor na resolução de problemas cotidianos inerentes à docência.

Em consonância com essa categoria, Marchesi (2008), discorre sobre algumas habilidades que considera essenciais para a satisfação na docência: (1) interesse do próprio docente no conhecimento que pretende desenvolver com seus alunos; (2) capacidade de relacionar o que é aprendido na sala de aula com aquilo que é vivenciado fora dela e, inversamente, levar para a sala de aula acontecimentos e experiências que acontecem à margem do trabalho escolar; (3) habilidades de promover o diálogo, a participação ativa e colaborativa dos alunos; (4) aceitação e criação de inovações.

O envolvimento com a pesquisa científica foi a quarta categoria emergida. Poder explorar ideias gerando resultados empíricos, que ampliam o conhecimento já adquirido, é percebido como fator de valorização e de orgulho para os docentes. A pesquisa é um dos aspectos a ser considerado como elemento estrutural na formação de professores, para possibilitar transições de concepções estáticas para concepções interativas e críticas da prática docente. A pesquisa pode subsidiar o desenvolvimento profissional, visto que abrange características que podem tanto ampliar quando aprofundar áreas do conhecimento relevantes aos professores.

A docência universitária exige a indissociabilidade entre ensino, pesquisa e extensão. Para tanto, a pesquisa associada à docência necessita interrogar o que se encontra fora do ângulo imediato de visão, para ampliar o conhecimento científico gerado pela academia, visando à melhoria da capacidade de decisão e de inferências sociais ofertadas aos discentes. Articular componentes curriculares e projetos de pesquisa e de intervenção exige o emprego de uma pluralidade metodológica que tanto pode ser desafiadora quanto motivadora na percepção dos docentes universitários (Veiga, 2006).

No entanto, a prática e o estímulo à pesquisa muitas vezes ficam restritos na/pela IES ao docente de pós-graduação ou àquele que possui vínculo permanente ou 
que ultrapasse um determinado número de horas, se for um professor horista. Essa política é pontada por muitos professores como um impedimento na ascensão profissional tendo em vista que a produção científica é um determinante na progressão da carreira docente, especialmente, quando envolve processos seletivos e de credenciamento institucional. Ou seja, este indicador sugere a necessidade de se repensar o quão efetivamente a participação na pesquisa científica é acessível a todo o corpo docente e aproveitada como promotora de motivação pelas IES.

Como quinta categoria de motivação para a permanência na carreira docente, emergiu a remuneração/salário. A remuneração por si mesma pode ser um motivador extrínseco, porém, quando aliada à satisfação dos quatro primeiros aspectos listados (relação com alunos, formação continuada, gosto/prazer/satisfação pela docência, envolvimento com a pesquisa científica), promove a motivação intrínseca (Deci \& Ryan, 2000, 2008). Alia-se a isto, a expectativa de muitos professores de que o aumento da titulação ou o ingresso em atividades de pós-graduação possam, a médio e longo prazo, produzir resultados financeiros mais satisfatórios.

Por outro lado, muitos docentes entrevistados (46,2\%) afirmaram também não ter dedicação exclusiva à docência, o que abre a possibilidade de atuação concomitante em outras atividades profissionais, tendo assim a possibilidade de ampliação de renda por meio da inserção no mercado de trabalho de sua área específica de formação. Porém, muitas vezes essa condição de não possuir vínculo de dedicação exclusiva obriga o docente a ter uma sobrecarga de trabalho, atuando em diferentes IES concomitantemente, acumulando funções e disciplinas que provocam desgaste físico e mental. Consideramos que apesar de outros fatores intrínsecos produzirem motivação para a permanência na docência, o investimento institucional e governamental na remuneração justa aos professores é uma premissa inquestionável para a valorização e qualidade da educação. Com isso, bons salários implicam reconhecimento da contribuição social da atuação docente, aspecto apontado a seguir.

A contribuição social da atuação docente foi a sexta categoria que emergiu das respostas professores. Alude ao importante papel do professor na sociedade em diferentes períodos da história da educação, mas principalmente pela contribuição nos processos de ensino e de aprendizagem na sociedade contemporânea. Os reflexos da prática docente podem ser percebidos nas ações do cotidiano dos discentes, pelo compromisso mútuo dos professores com os princípios e objetivos do ensino, adicionados a responsabilidade de conectar a teoria à prática. Além disso, a educação superior tem como meta primordial a formação de novas gerações de profissionais em áreas específicas e, nesse processo, a identificação do discente com o docente, o qual funciona como um modelo de profissional, permite aproximações que potencializam a valorização profissional e construção da identidade profissional. Anastasiou (2006) defende práticas e atitudes que permitam desenvolver processos articulados, com foco direcionado para a construção da cidadania nos educandos. A contribuição social da atuação docente envolve, portanto, o movimento para a formação do ser humano em sua integralidade, com capacidade de criticar mediante suas inquietações, mas de atuar eticamente no exercício de sua profissão e condutas pessoais.

$\mathrm{O}$ ambiente acadêmico, sétima categoria que emergiu para a permanência na docência entre os professores pesquisados, necessita de especial atenção para ser e estar adequado às demandas e às premissas educacionais pautadas no respeito mútuo. Por isso,as trajetórias formativas dos professores e da IES estão inter-relacionadas e o modo como são vividas e percebidas determina o propósito pessoal/grupal e institucional de transformação e aperfeiçoamento em direção a um ideal formativo comum. Em razão disso, instituições e professores necessitam estar conscientes de suas responsabilidades formativas, sendo verdadeiras incubadoras de ideias e inovações, que estimulem não apenas a competência, mas, sobretudo, os valores humanos. Tavares (2007) corrobora essa premissa ao apontar que é o ambiente inquietante, desafiador e questionador oportunizado pela academia, que atrai muitos profissionais para a carreira a docente.

Na mesma ordem de relevância, na percepção dos professores entrevistados, estão as últimas categorias: autonomia, segurança/estabilidade/prestígio e desafios/ compartilhamento do conhecimento. Neste estudo os professores fizeram referência à autonomia como a liberdade de fazer algumas escolhas tanto no plano didático e metodológico como na flexibilização de horários e atividades, vinculando o conceito à ideia de independência. No entanto, não podemos eximir o significado de autonomia da noção de comprometimento voluntário do professor com seus valores, suas práticas, seus educandos e a instituição em que trabaIha, sendo essencial para a motivação autorregulada (Deci \& Ryan, 2009).

A finalidade das instituições de ensino, segundo Pérez-Gomes (2011), não pode ser puramente o ensino de conteúdos disciplinares, mas sim, o desenvolvimento singular de cada indivíduo. A educação na contemporaneidade requer dos sistemas educativos a personalização dos processos de ensino e de aprendizagem para atender a diversidade e fortalecer a singularidade dos projetos pessoais, tanto de estudantes como de professores. A visão peculiar e individual reflete-se na autonomia, por tratar das necessidades pessoais e, consequentemente, na motivação intrínseca.

Neste sentido, Hennemann e Portella (2012) entendem a motivação com significado próximo ao de emancipação, onde há o controle do indivíduo sobre si mesmo e como capacidade de definir suas vontades, seus desejos, distinguindo-se dos demais. No exercício da docência, o professor autônomo terá mais condições de promover o processo motivacional dos estudantes, na medida em que a autonomia pode estar relacionada com a cooperação e vínculos afetivos consistentes (Santos, Mosquera, Stobäus, Antunes, \& Bernardi, 2012).

Questões como segurança, estabilidade e prestígio também se configuraram categorias para a permanência 
na carreira docente. Para muitos professores o plano de carreira, a nomeação via concurso e a garantia de titularidade no cargo são atrativos na docência, equivalendo-a a outras categorias profissionais, muito embora saibamos que essa não é a única realidade dos professores, muitos dos quais são horistas, por exemplo. Pensamos que questões administrativas e trabalhistas nomeadas entre os fatores que motivam os docentes para a permanência na carreira apontam para a postura profissional menos idealizada e mais convicta dos direitos e do respeito que lhes são devidos. Pensar na docência também como uma opção profissional, contrapondo-se à perspectiva histórica de "sacerdócio" ou de "ocupação feminina", é um passo importante no fortalecimento da qualidade da educação no país.

Outra categoria apontada, desafios e compartilhamento do conhecimento, retrata como positiva a existência de desafios na prática docente, tendo em vista a busca constante de novos conhecimentos, a reciprocidade de trocas entre pares, a aprendizagem com alunos e o processo de autoconhecimento e reflexividade. Entendemos assim, que a dinâmica do processo de aprendizagem compreende as dimensões interpessoal e intrapessoal. Para Isaia (2006), a dimensão interpessoal indica que a aprendizagem de ser professor não pode ser um processo solitário, abrangendo a interação com colegas e alunos, o espaço acadêmico e a comunidade, em seu conjunto. Envolve também o estabelecimento de relações sociais e interpessoais que sustentam a noção de pertencimento fundamental para o bem estar promotor de motivação, segundo a SDT.

Zabalza (2004) compreende que o rompimento da cultura individualista pelas IES é o primeiro passo para a construção efetiva do desenvolvimento profissional docente e, consequentemente, da formação de cada professor. Portanto, tornar-se professor ocorre na relação com os outros e nas mediações e interações que acontecem no trabalho cooperativo.

Já a aprendizagem intrapessoal, segundo Isaia (2006), leva em conta o processo de internalização de tudo o que foi vivido nos contatos externos. Assim, a integração entre interpessoal e intrapessoal só pode efetivar-se em um docente consciente de sua atuação e de sua responsabilidade como educador e mediador. Para a autora, a prática docente desenvolvida pela aprendizagem inter e intrapessoal estimula a aprendizagem colaborativa, uma vez que explora diálogos e ferramentas culturais que desafiam cognitivamente os docentes a avançar em direção aos seus potenciais ainda inexplorados.

Os processos de ensinar e aprender atuais são diferentes das épocas passadas. Os novos objetivos e sujeitos da educação exigem profundas transformações na seleção e interpretação dos conceitos que devem ser aprendidos, nos sistemas de avaliação e na metodologia de ensino. É preciso "ensinar" de outra maneira para que os alunos participem mais ativamente do processo de aprendizagem. Um ensino que supõe pensar os lugares, tempos, relações e formas em que se concretize em cada ambiente o processo de ensinar e de aprender. É necessário conceber o ensino a partir de uma visão mais ampla e global, detectando as diferentes formas que têm os alunos para aproximarem-se da informação e do conhecimento (Pérez -Gomes, 2011).

A docência é, pois, uma atividade profissional complexa pelos saberes e que requer. Logo, o papel docente consiste não propriamente em ensinar ou transmitir, mas em suscitar questões, problematizar, instigar a curiosidade, orientar para a busca de respostas, ajudar a relacionar, aprofundar e sintetizar. Diante desse cenário, parece que os desafios podem ser percebidos pelos professores como propulsores de motivos para a permanência e o desenvolvimento na carreira docente.

\section{Considerações Finais}

Os resultados desta pesquisa, embora incipientes e oriundos de uma amostra específica, convergem com a literatura atual sobre a temática, especialmente com as teorias contemporâneas sobre os processos motivacionais. Evidenciaram que os motivos de permanência na profissão docente referidos pelos professores pesquisados contemplam, principalmente, aspectos motivacionais intrínsecos, ou seja, que possuem um valor subjetivo e não tangível. Esses motivos (categorias) quando compreendidos à luz da SDT, podem ser associados às necessidades psicológicas básicas de autonomia (por exemplo, o gosto/prazer e satisfação pela docência), competência (por exemplo, a formação continuada) e pertencimento (por exemplo, a relação com os alunos e o ambiente acadêmico), necessidades estas fundamentais para desenvolver nos docentes maior engajamento com as atividades que fazem parte da sua prática e bem-estar na profissão.

Contudo, é necessário ter presente que essas necessidades podem ser percebidas de modo diverso por diferentes sujeitos ou sob circunstâncias distintas; ou serem mais ou menos satisfeitas de acordo com o que o contexto permite ou oferece, de modo que um mesmo fator pode se refletir em mais de uma necessidade psicológica. Além disso, essas necessidades são totalmente correlacionadas, ou seja, a frustração de uma tende a afetar a satisfação das demais.

Apenas duas categorias emergidas, salário/remuneração e ambiente acadêmico, remetem à valoração de aspectos de recompensa ou contingências sob controle externo, vinculados, a priori, à motivação extrínseca. Contudo, a natureza dinâmica e sistêmica dos processos motivacionais permite inferir que elementos intrínsecos e extrínsecos são intercambiáveis, podendo ser mais ou menos internalizados ao self de acordo com as experiências, de forma que não ocupam uma posição rígida e cristalizada.

A escuta do que é percebido pelos professores, em si mesmos e no seu contexto, consiste na melhor maneira de atribuirmos significado e nexo às múltiplas questões que compõem a motivação para a permanência na carreira docente. É sempre desejável que essa permanência possa ser resultado do engajamento prazeroso com sua escolha, esta movida pelo sentimento de autonomia e bem-estar. Professores comprometidos, inquietos e orgulhosos de seu 
papel docente representam modelos indispensáveis às novas gerações de profissionais que o meio universitário se propõe a formar. Por isso, reconhecer, promover e estimular condições que despertem o desejo de permanecer na docência, além de uma meta de cada professor, pautada no autoconhecimento e na autorregulação de seus objetivos, deve ser compromisso da gestão governamental e institucional preocupada com a qualidade da educação. Mas para tanto não podemos, arbitrariamente, elencar aspectos motivadores, senão produzir evidências empíricas contextualizadas que orientem as prioridades e interesses dos docentes.

Acreditamos que as categorias que emergiram como motivos para a permanência na carreira docente podem oferecer subsídios empíricos que contribuam, juntamente com o conhecimento já acumulado sobre a temática, para o estabelecimento de correlações entre fatores individuais, contextuais e motivação percebida, úteis na promoção do desenvolvimento e da qualidade da docência na educação superior. Nesse sentido, esses resultados qualitativos apresentam potencial significativo para apoiar a construção de instrumentos (tais como, escalas, questionários padronizados)que permitam investigar a motivação de docentes universitários de modo sistemático, promovendo o aprofundamento da temática, bem como a avanços no campo teórico. Além disso, visando dar consistência aos resultados atuais, este estudo poderia ser replicado estendendo-se a outros contextos institucionais e categorias administrativas das IES, visando examinar se a percepção de outros sujeitos reproduz as categorias encontradas.

Por outro lado, a devolução desses achados às instituições de ensino pode representar uma medida de suma importância, perante a possibilidade de implementação de ações que contribuam para a promoção da motivação que instiga a permanência na carreira docente. Dar espaço e voz à subjetividade dos professores, estando atento às suas implicações no âmbito coletivo do contexto universitário, é um desafio que demanda por investimentos voltados, sobretudo, à produção de novos conhecimentos, cujas pesquisas realizadas no próprio meio acadêmico representam um caminho viável para isso.

\section{Referências}

Anastasiou, L. G. C. (2006). Docência na educação superior. Em D. Ristoff \& P. Savegnani. (Org.), Docência na Educação Superior. Brasília: Instituto Nacional de Estudos e Pesquisas Educacionais Anísio Teixeira, 147-172.

Bardin, L. (2011). Análise de conteúdo. São Paulo: Edições 70.

Bittar, M., Oliveira, J. F., \& Morosini, M. (Orgs.). (2008). Educação superior no Brasil - 10 anos pós LDB. Brasília: Instituto Nacional de Estudos e Pesquisas Educacionais Anísio Teixeira.

Deci, E. L. \& Ryan, R. M. (2000). Self-Determination Theory and the Facilitation of Intrinsic Motivation, Social Development, and Well-
Being. American Psychologist, 55 (1), 68-78. Recuperado: 12 ago. 2014. Disponível: http://dx.doi.org/10.1037/0003-066X.55.1.68

Deci, E. L. \& Ryan, R. M. (2008). Self-Determination Theory: A Macrotheory of Human Motivation, Development, and Health. Canadian Psychology, 49 (3), 182-185. Recuperado: 15 set. 2014. Disponível em: http://dx.doi.org/10.1037/a0012801

Gil, A. C. (2012). Didática do ensino superior. São Paulo: Atlas.

Grillo, M. \& Mattei, P. (2005). Saberes docentes, identidade profissional e docência. Em D. Enricone \& M. Grillo (Orgs), Educação Superior. vivências de futuro. Porto Alegre: EDIPUCRS, 99-110.

Hennemann, M. F. \& Portella, F. O. (2012). O processo motivacional e a autonomia escolar. Em B. S. Santos, D. D. Antunes \& J. Bernardi. (Orgs.), Processos motivacionais em contextos educativos: teoria e prática. Portugal: Edições Pedagogo, 175-190.

Huertas, J.A. (2001). Motivatión: quere aprender. Buenos Aires: Aique.

Isaia, S.M.A. (2006). Desafios à docência superior: pressupostos a considerar. Em D. Ristoff \& P. Savegnani. (Orgs), Docência na educação superior. Brasília: Instituto Nacional de Estudos e Pesquisas Educacionais Anísio Teixeira, 63-84

Jesus, S. N.(1996). A motivação para a profissão docente: Contributo para a clarificação de situações de mal-estar e para a fundamentação de estratégias de formação de professores. Portugal: Estante Editora.

Jesus, S. N. (2004). Psicologia da educação. Coimbra: Quarteto.

Jesus, S. N. \& Santos, J. C. V. (2004). Desenvolvimento Profissional e Motivação dos Professores. Educação: Revista da Faculdade de Educação, 27(52), 39-58.

Kanfer, R. (1995). Motivation and performance. Em N. Nicholson (ed.) Blackwell Encyclopedic Dictionary of Organizational Behavior. Oxford: Blackwell, 330-338.

Matos, S. S. \& Hobold, M. S. (2015). Constituição de Sentidos Subjetivos do Processo Ensino e Aprendizagem no Ensino Superior Psicologia Escolar e Educacional, 19(2), 299-308. Disponível em: https://dx.doi.org/10.1590/2175-3539/2015/0192838

Marchesi, A. (2008). O bem-estar dos professores. Porto Alegre: Artmed.

Morosini, M. C. \& Rossato, R. (2006). Educação superior no Rio Grande do Sul: 1991 - 2004. Em INEP (Org.), Educação Superior Brasileira: 1991-2004. Brasília: Instituto Nacional de Estudos e Pesquisas Educacionais Anísio Teixeira, 24-77.

Pérez-Gomes, A. L. (2011). Aprender a educar (se): una nueva ilustración para la escuela. Cuadernos de Pedagogía, 417,52-55. 
Sánchez-Sellero, M. C., Sánchez-Sellero, P., Cruz-González, M. M., \& Sánchez-Sellero, F. J. (2014). Organizational characteristics in thelabour satisfaction in Spain. Revista de Administração de Empresas, 54(5), 537-547. Recuperado: 19 out. 2014. Disponível: https://dx.doi.org/10.1590/S0034-759020140507

Santos, B. S. \& Antunes, D. D. (2013). Formação docente: processos motivacionais e subjetividade. Em A. A. C. Bezerra \& M. B. C. Nascimento (Orgs.), Educação e formação de professores: questões contemporâneas. Fortaleza: Edições UFC, 297-330.

Santos, B. S., Mosquera, J. J. M., Stobäus, C. D., Antunes, D. D. \& Bernardi, J. (2012). Oficinas de autoconhecimento e motivação docente. Em B.S. Santos, D. D Antunes \& J. Bernardi (Orgs.), Processos motivacionais em contextos educativos: teoria e prática. Portugal: Edições Pedagogo, 105-125.

Silva, M. G. M. \& Beraldo, T. M. L.(2008). Universidade, sociedade do conhecimento, educação: o trabalho docente em questão. Em M. Bittar, J. F. Oliveira, \& M. Morosini (Org.), Educação superior no Brasil - 10 anos pós LDBI. Brasília: Instituto Nacional de Estudos e Pesquisas Educacionais Anísio Teixeira, 307-326
Tardif, M. (2013). Saberes docentes e formação profissional. Petrópolis: Vozes.

Tavares, J. (2007). Aprendizagem e competências: impactos na sociedade. Em M. E. A. Engers \& M. C. Morosini (Orgs.), Pedagogia universitária e aprendizagem. Porto Alegre: Edipucrs, 59-73.

Veiga, I. P. A. \& Viana, C. M. Q. Q. (2011). Formação de professores: um campo de possibilidades inovadoras. Em I. P. A. Veiga \& E. F. Silva. (Org.), A escola mudou, que mude a formação de professores. Campinas: Papirus Editora, 13-34.

Veiga, I. P. A. (2006). Docência universitária na educação superior. Em D. Ristoff \& P. Savegnani. (Orgs.), Docência na educação superior. Brasília: Instituto Nacional de Estudos e Pesquisas Educacionais Anísio Teixeira, 85-96

Zabalza, M. (2004). O ensino universitário: Seu cenário e seus protagonistas. Porto Alegre, RS: Artmed.

\section{Sobre as autoras}

Tárcia Rita Davoglio (tarciad@gmail.com)

Doutora em Psicologia, Pós-Doutorado em Educação, Programa de Pós-Graduação em Educação/PPGEDU, Escola de Humanidades, Pontifícia Universidade Católica do Rio Grande do Sul /PUCRS.

Carla Spagnolo (carla.spagnolo@acad.pucrs.br)

Doutora em Educação, PPGEDU/PUCRS.

Bettina Steren dos Santos (bettina@pucrs.br)

Doutora em Psicologia Evolutiva e da Educação, Pós-doutorado no College of Education UT/E. PPGEDU/PUCRS.

\section{Apoio Financeiro}

CNPq - Conselho Nacional de Desenvolvimento Científico e Tecnológico

FAPERGS - Fundação de Amparo à Pesquisa do Estado do Rio Grande do Sul (Edital DOCFIX CAPES/FAPERGS 09/2012)

O projeto que abarca esta pesquisa foi submetido ao Comitê de Ética em Pesquisa da PUCRS (CEP 10/05132) 